\title{
The Mystery of Chemotherapy Brain: Kynurenines, Tubulin and Biophoton Release
}

\author{
PETER P. SORDILLO ${ }^{1}$ and LAURA A. SORDILLO ${ }^{2}$ \\ ${ }^{1}$ Department of Hematology-Oncology, Lenox Hill Hospital, New York, NY, U.S.A.; \\ ${ }^{2}$ Departments of Physics and Electrical Engineering, The City College of New York, New York, NY, U.S.A.
}

\begin{abstract}
The majority of patients receiving chemotherapy experience post-chemotherapy cognitive impairment, sometimes referred to as "chemo brain" or "chemo fog." The cognitive impairment associated with this syndrome can be severe, and can sometimes last for many years after therapy discontinuation. Despite extensive investigations, its etiology is unknown. We argue that chemo brain results from damage to tubulin within microtubules. This damage can occur directly from tubulin inhibitors such as taxanes, epothilones or vinca alkaloids. Other chemotherapies stimulate increased mitochondrial activity and biophoton release. This results in abnormal tryptophan metabolism and excess production of neurotoxic kynurenines, which, in turn, damage microtubules.
\end{abstract}

Chemotherapy drugs can have severe toxic effects on any organ in the body and the mechanisms by which most of these toxicities occur are well understood. The exception is "chemotherapy brain" (chemo brain). Up to $75 \%$ of patients receiving chemotherapy experience some degree of neurocognitive impairment (1), a clinical syndrome which manifests as difficulties with concentration, decision-making and learning, memory loss, and problems with comprehension. This is the so-called chemo brain (2-9). This general "slowness" of neurocognitive activity without other symptoms is characteristic of chemo brain. Auditory, tactile or visual hallucinations, signs of dementia, tremors, sensory impairments and problems with motor strength are not considered part of this syndrome. The "fog" these patients experience is the defining

This article is freely accessible online.

Correspondence to: Peter P. Sordillo, MD, Ph.D., 51 East $82^{\text {nd }}$ Street, New York, NY 10028, U.S.A. Tel: +1 2127375706, e-mail: peldv1@gmail.com

Key Words: Chemo brain, tryptophan, kynurenine, NAD, tubulin, cognition, biophoton, review. feature of chemo brain. Despite numerous investigations into the etiology of this syndrome, the cause is unknown.

Although the mechanism by which chemo brain occurs is not understood, it occurs commonly. For example, Iyer et al. reviewed ten studies of 509 children with acute lymphoblastic leukemia (ALL) who had received chemotherapy but not cranial radiation. The protocol of treatments for ALL patients almost always includes drugs of the vinca alkaloid (primarily vincristine) and anthracycline (doxorubicin or daunorubicin) classes (4). Children who received these chemotherapies demonstrated decreases in memory and information processing speed, as well as a reduction in IQ by 6-8 points compared to that of 555 age-matched controls. Kessler et al. studied breast cancer patients who had received doxorubicin-containing regimens, chemotherapy regimens without doxorubicin or no chemotherapy. Both chemotherapy groups demonstrated greater memory and other cognitive impairments compared to women who had not received chemotherapy, with greatest impairments in women who had received doxorubicin (9). Similar results have been reported in breast cancer patients receiving cyclophosphamide, methotrexate and 5-fluorouracil (10), or various chemotherapy regimens for adults with either lymphoma or breast cancer (11). There is also experimental evidence that documents the deterioration of cognitive functioning after chemotherapy. Rendeiro et al. observed cognitive impairments, similar to those in patients, in C57BL/6J mice treated with cyclophosphamide, doxorubicin and 5-fluorouracil (12).

There is no clear explanation why patients experience these cognitive changes, why these symptoms may be so severe or persistent, or why they occur in the absence of other impairments. Seemingly obvious explanations, such as that these symptoms are due to the psychological stress of cancer diagnosis, are not consistent with the fact that the symptoms can persist years after treatment. More importantly, cancer patients who receive adjuvant chemotherapy after surgery have a higher incidence of chemo brain than those who undergo surgery alone. It is also important to note that most chemotherapy drugs strongly associated with chemo brain do not cross the blood 
brain barrier or cross only in low concentrations. Although some studies have suggested that treatments can themselves open up the blood brain barrier, other studies do not support this conclusion (13). This suggests that the mechanism of chemo brain is unlikely to be a direct effect on neurons, but, rather, that chemotherapy acts indirectly.

\section{Pro-inflammatory Cytokines}

Chemotherapy is well-known to increase production of proinflammatory cytokines. Reers et al. demonstrated that head and neck cancer cell lines exposed to 5-fluorouracil and cisplatin increased their secretion of tumor necrosis factoralpha (TNF-alpha), interleukin-1beta (IL-1beta) and IL-6 (14). Edwardson et al. showed that multiple chemotherapy agents, including docetaxel, increased the release of TNF-alpha and CXCL1 from breast and ovarian cancer cells (15). Penson et al. showed that another taxane drug significantly increased IL6, IL-8 and MCP-1 (16). Pusztai et al. studied 90 breast cancer patients who received either FAC chemotherapy (5fluorouracil, doxorubicin and cyclophosphamide) or paclitaxel monotherapy. Marked increases in IL-6, IL-8 and IL-10 were observed (17). In another study, women with breast cancer had increased levels of TNF-alpha and IL- 6 at 6 and at 18 months after completion of therapy compared to controls (18). Jones et al. described how these chemotherapy-induced cytokines mediate resistance to treatment, and accelerate tumor growth and development of metastases (19). IL-6 and other cytokines predispose to development of cancer stem cells, which are resistant to further chemotherapy and radiation (20). Others have also described how cancers stimulate cytokines to insure their survival (21-23). Antineoplastics such as oxaliplatin, fludarabine, lenalidomide, rituximab and nivolumab can sometimes even cause a potentially fatal cytokine storm with massive releases of TNF-alpha, IL-1 beta, IL-6, IL-8, interferon gamma, IL-5, IL-13 and IL-10 (24-26).

There is a close association of the increase in proinflammatory cytokines with chemo brain (27). Ganz et al. and others have suggested that TNF-alpha may be the cause of chemotherapy brain, since higher levels of this cytokine correlate with greater neurocognitive symptoms, and improvements in neurocognitive symptoms parallel with decreasing TNF-alpha levels (28). Tangpong et al. studied mice treated with doxorubicin and obtained no evidence that this drug crossed the blood brain barrier. However, there was strong TNF-alpha immunoreactivity within the brain, and there was also evidence of damage to brain mitochondria and increased expression of pro-apoptotic proteins like BAX and p53 (13). Others have suggested that increased levels of IL1 beta, IL- 6 or interferon gamma, or decreased levels of antiinflammatory cytokines like IL-4 or IL-10 may be causally involved in chemo brain (29-30). For example, Cheung showed that higher levels of IL-1 beta and IL-6 were associated with greater cognitive impairments, while higher levels of the anti-inflammatory cytokine, IL-4, were protective (31). Dunlop and Campbell have discussed how chemotherapy-induced cytokines can cause symptoms of chemo brain and other poorly-defined symptoms like generalized pain and malaise (32). There is also direct evidence that cytokines can cause a clinical syndrome like chemo brain. Capuron et al. performed neurocognitive tests on 47 patients who had received IL-2 or interferon-alpha as cancer treatment. Patients who received these treatments developed impaired spatial memory, longer latencies in reaction time and decreased accuracy in planning tasks (33).

Cytokines have been shown to cause damage to the brain and other tissues in multiple ways (34-36). Unlike most chemotherapies, cytokines can freely cross the blood brain barrier $(37,38)$. They may accumulate massively after infections or injury; and although cytokines can have beneficial effects, they can be responsible for damage to the brain tissue beyond that caused by the initial insult (39-41). For example, cytokines stimulate matrix metalloproteinases, which are zinc-based enzymes which digest tissue. These enzymes are linked to the development of many diseases, including Alzheimer's (42-45).

\section{Mitochondrial Biophoton Emission}

There is an important mechanism by which cytokines may cause neurocognitive impairments by dramatically increasing (and are increased by) reactive oxygen species (ROS) (46, 47). ROS are involved in countless metabolic processes that are essential for life, including adenosine triphosphate production, response to pathogens, cellular homeostasis and cell signaling (48-50). ROS have also been postulated by many to be causally involved in chemo brain $(38,51)$. Anthracyclines like doxorubicin have been shown to result in the production of extremely high levels of $\operatorname{ROS}(37,38,52)$. Anthracycline-induced TNF-alpha secretion has been shown to cause damage to mitochondria (13). Tangpong et al. studied doxorubicin-induced nitration of manganese superoxide dismutase, resulting in a reduction in mitochondrial anti-oxidant activity in the mouse brain. The mice developed symptoms similar to those of patients with chemo brain (53). Likewise, Keeney et al. showed that doxorubicin induced TNF-alpha and caused similar symptoms through oxidative stress (54). Cisplatin also markedly increases ROS levels, and this is a mechanism by which this drug may destroy cancer cells $(55,56)$. The cytokines TNFalpha and IL-1 beta have been shown to cause mitochondrial DNA damage in chondrocytes (57). Lopez-Armada et al. demonstrated that mitochondrial activity in chondrocytes is regulated by these two cytokines (58). Many other chemotherapeutic agents, including alkylating agents, arsenic, topotecan and irinotecan, also increase $\operatorname{ROS}(48,51,59)$. 
Reactions involving ROS in living tissues, including all animals and plants, have been shown to cause the continuous release of photons from mitochondria, which are emitted as excited electrons return to the ground state (60-69). These biophotons are primarily in the ultraviolet and visible ranges $(100-800 \mathrm{~nm})$, but may also extend to the infrared $(70,71)$. Measurements of photon release have been used to monitor ROS production (72). These biophotons can then be absorbed and emitted at different wavelength by chromophores like flavins, collagen, NADH and tryptophan (Table I). Significant release of biophotons occurs at $280 \mathrm{~nm}$, which corresponds to the peak absorption wavelength of the essential amino acid, tryptophan, a highly fluorescent chromophore $(66,73)$.

\section{Tryptophan Fluorescence}

Exposure of materials containing tryptophan to ultraviolet (UV) light will result in the metabolism of this amino acid along the kynurenine pathway (Figure 1). Photoyellowing of wool products after exposure to light results mostly from the stimulation of the metabolism of tyrosine and (primarily) tryptophan, and production of metabolites such as kynurenine, hydroxykynurenine and $\mathrm{N}$-formylkynurenine (74). Schafer et al. showed again that photo-generation of kynurenines from tryptophan and photoyellowing of wool entails a key role for oxygen (75). Other studies have demonstrated that these metabolites are major ultraviolet-photooxidation products of tryptophan (76). Hamdy et al. exposed tryptophan to various light sources and demonstrated that UVB light markedly increased metabolism along this pathway (77). Sheipouri et al. have shown that UV skin damage correlates with production of kynurenines from tryptophan (78). The damage to the lens of the eye with sun exposure is caused primarily by UV light. Andley et al. showed that UV light stimulates the generation of superoxide anion $\left(\mathrm{O}_{2^{-}}\right)$and hydrogen peroxide. The authors also found a decrease in tryptophan fluorescence and an increase in fluorescence by tryptophan metabolites, consistent with stimulation of the kynurenine pathway (79). Linetsky et al. showed that metabolites of tryptophan through the kynurenine pathway modify proteins in the lens after exposure to UV light (80). This same mechanism also occurs within the brain, and is associated with the cytokines, interferon gamma and TNF-alpha, which stimulate excess production of the enzymes, indoleamine 2,3-dioxygenase and tryptophan 2,3dioxygenase. Increased cytokines levels result in greater release of biophotons from mitochondria in the brain. Toxic levels of kynurenines are associated with the development of many neurological diseases, including Parkinson's disease $(81,82)$, Huntington's chorea (83), amyotrophic lateral sclerosis (84) and Alzheimer's (85), as well as glioblastoma resistance to treatment $(86,87)$. IL-1 beta has also been shown to regulate this important pathway (88). Metabolites formed by excessive kynurenine pathway activity have major neurotoxic effects on
Table I. Key biomolecules with corresponding absorption and emission peak maxima $(\mathrm{nm})$.

\begin{tabular}{lcc}
\hline Biomolecule & Absorption $(\mathrm{nm})$ & Emission $(\mathrm{nm})$ \\
\hline Tryptophan & 280 & 340 \\
Collagen & 339 & 380 \\
NADH & 340 & $440-460$ \\
Flavins & 375 & 525 \\
Tyrosine & 275 & 303 \\
\hline
\end{tabular}

brain tissue. Quinolinic acid can cause axonal degeneration, acute brain cell death $(89,90)$, hallucinations, delusions and bizarre behavior. Quinolinic acid is also known to have important effects on microtubules. Quinolinic acid plays a role in Alzheimer's disease pathogenesis by affecting Tau phosphorylation and causing disassembly of microtubules (91). This results in death of neurons and memory loss (92). Excess levels of quinolinic acid have been linked to Huntington's chorea, AIDS dementia, cognitive decline of aging, malariaassociated neurotoxicity and multiple sclerosis $(93,94)$. Rats receiving intrastriatal injections of quinolinic acid experience alterations of microtubule-associated protein-2 and cytoskeletal disruption (95). Another tryptophan metabolite, 3hydroxykynurenine, can cause hallucinations and is thought to play a role in the development of schizophrenia and bipolar disorder $(96,97)$. High levels of 3-hydroxykynurenine correlate strongly with increased schizophrenic symptoms. 3hydroxykynurenine may also cause increased beta-amyloid accumulation in the brains of patients with Alzheimer's disease (98). Both of these neurotoxic tryptophan metabolites have been linked with the development of major depressive disorders (99). Importantly, abnormal levels of kynurenines are associated with cognitive impairments in individuals without these diseases. Solvang et al. studied 2174 adults, aged 70-72 years old, living in an adult community. They found that increasing kynurenine/tryptophan ratios correlated with greater impairments of cognitive functions (100).

\section{Microtubules}

Microtubules are cylindrical structures in the cytoskeleton of eukaryotic cells. They are composed of polymers of alpha and beta-tubulin, and are key to proper functioning of multiple cellular processes, including intracellular transport and cell movement. Most importantly, microtubules are important for both mitosis and meiosis (101-106). For this reason, tubulin has become a major target of chemotherapy drugs. Abnormalities in microtubules have long been associated with cognition and memory problems (107), and damage to microtubules correlates with numerous neurological diseases. Microtubules play a key role in neurocognitive development and abnormalities in 

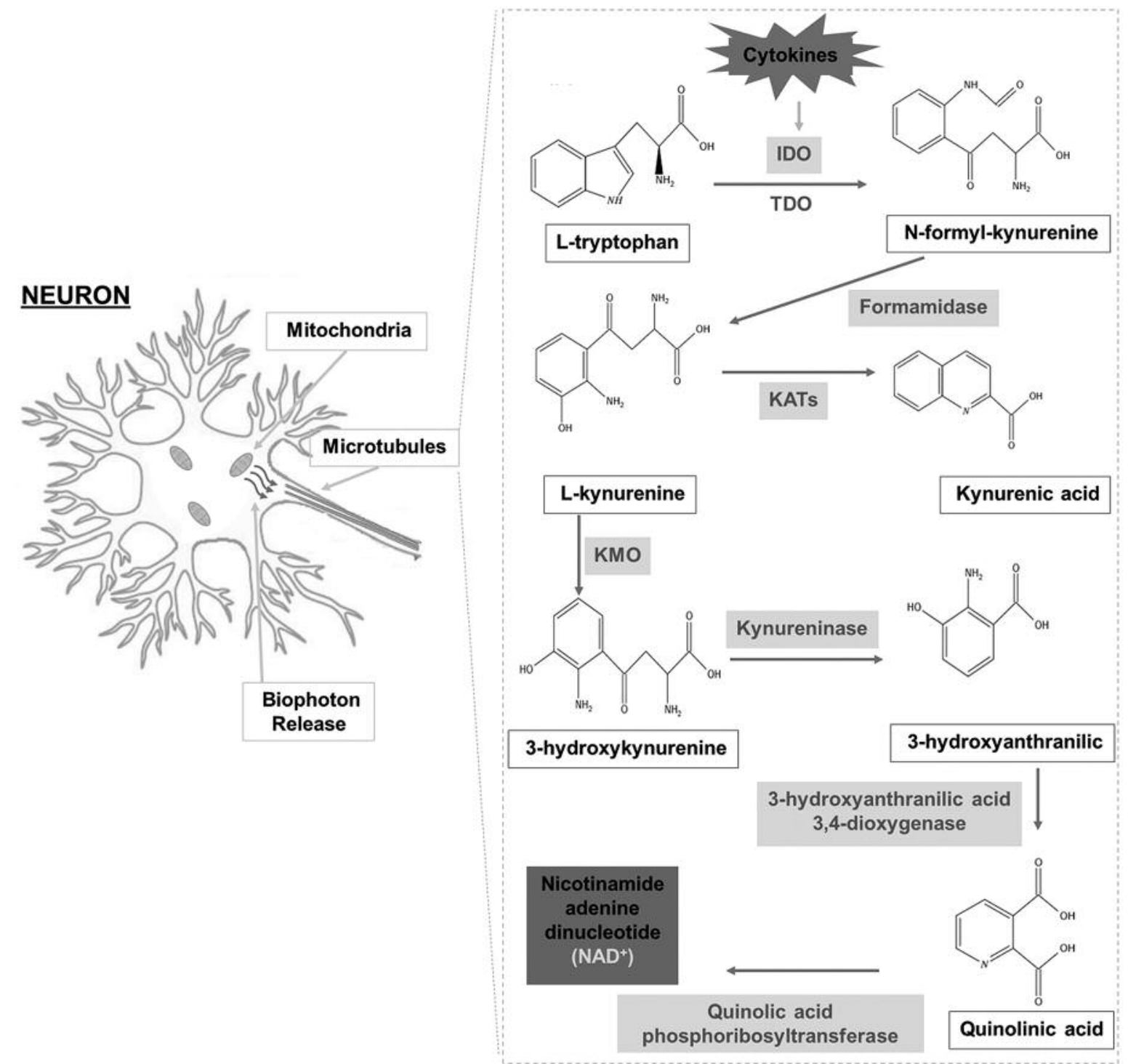

Figure 1. Neuron with mitochondria (biophoton release) and microtubules (not to scale). Tryptophan metabolism (in the microtubules) in the kynurenine pathway. IDO: Indoleamine 2,3-dioxygenase; TDO: tryptophan 2,3-dioxygenase; KAT: kynurenine aminotransferases; KMO: kynurenine 3-monooxygenase.

microtubules may result in intellectual impairments and autism (108). The enzyme, NAD-dependent deacetylase sirtuin 2 (SIRT 2), which concentrates in neural tissue and is associated with diseases like Alzheimer's, Huntington's chorea and Parkinson's, deacetylates tubulin (109). NAD is a major metabolite of quinolinic acid and is produced through the activity of quinolinate phosphoribosyltransferase (110).

Numerous studies have demonstrated that these mitochondrial biophotons, including those that originate in neural cells, have profound effects on microtubules (66). Both mitochondria in the cytoskeleton and closelyassociated microtubules have a much higher refractive index than surrounding tissues, and these systems can act like optical waveguides $(111,112)$. There is also evidence that, while a physiological level of mitochondrial ROS and normal biophoton release correlates with normal brain functioning, including synaptic plasticity and memory consolidation (112-114), increased or decreased photon release is associated with neural pathology. It is notable that increased biophoton release can alter the orientation of microtubules. The greatest alteration in the orientation of the microtubules occurs when the wavelength of the biophotons is at $280 \mathrm{~nm}$, which is the peak absorption wavelength of tryptophan $(66,73,115)$. 
Table II. Commonly-used chemotherapeutics which act as tubulin inhibitors.

\begin{tabular}{ll}
\hline Drug & Indication \\
\hline Paclitaxel (Taxol) & Breast, non-small cell lung, ovarian, pancreatic and head and neck carcinoma, Kaposi's sarcoma \\
Docetaxel (Taxotere) & Breast, non-small cell lung, prostate, head and neck, gastric and ovarian carcinoma \\
Nab-paclitaxel (Abraxane) & Breast, non-small cell lung and pancreatic carcinoma \\
Ixabepilone (Ixempra) & Breast carcinoma \\
Erbulin Mesylate (Halaven) & Breast carcinoma, liposarcoma \\
Vincristine (Oncovin) & Acute lymphoblastic leukemia, Hodgkin's disease, multiple myeloma, Wilm's tumor, Ewing's sarcoma, \\
& neuroblastoma, lymphomas, adult soft-tissue sarcomas, thyroid carcinoma \\
Vinorelbine (Navelbine) & Rhabdomyosarcoma, breast and non-small cell lung carcinoma \\
Vindesine (Eldisine) & Non-small cell lung and breast carcinoma, lymphoma, leukemia \\
Vinblastine (Velban) & Hodgkin's disease, bladder, testicular and non-small cell lung carcinoma \\
\hline
\end{tabular}

Not only is there evidence that excess biophoton release can cause neurological impairments, the correlation of photon release measurements with other brain function measurements provide additional support for this hypothesis. Kobayashi et al. have shown a correlation of the levels of photon release with cerebral energy metabolism (61). Isojima et al. reported similar results (116). Van Wijk et al. have shown there is a correlation between the level of photon emission with the strength of alpha rhythms observed on the electroencephalogram (EEG) (117). Further, it has been reported that synchronous EEG patterns correlate with various neurocognitive states. Melloni et al. demonstrated that EEG readings showing synchronization of neural activity across areas of the cerebral cortex correlate with conscious perception (118). Synchronization of oscillatory phases between different brain regions promotes neural plasticity and correlates with long-term memory (119). Fries showed that neuronal gamma-band synchronization correlates with cortical computation (120).

\section{Post-anesthesia Cognitive Impairment}

The clinical syndrome of post-anesthesia cognitive impairment (PACI), sometimes referred to as post-surgical cognitive impairment, includes difficulties in concentration, comprehension and memory that occur after anesthesia, and is remarkably similar to the chemo brain. It is thought to be a separate clinical entity than post-operative delirium, and is listed in the DSM-5 (Diagnostic and Statistical Manual of Mental Disorders) as such (121). In the absence of other factors (advanced age, pain medications, alcohol abuse), it does not involve hallucinations or delusions or other signs of dementia. Furthermore, it does not involve tremors or gross sensory or motor impairments (122-124). PACI can last for months or years, while post-operative delirium is usually short-lived (121). As with chemo brain, pro-inflammatory cytokines are thought to have a role in the causation of PACI. Cibelli et al. performed tibial surgery on knockout mice lacking the IL-1 beta receptor and on wild-type mice. PACI developed only in the knockout mice. Mice treated with IL-1 beta receptor antagonist also did not develop PACI (125). Terrando et al. reported that TNF-alpha could stimulate release of IL-1 in the brain and thus cause PACI (126). The anesthetic isoflurane has been shown to increase brain levels of TNF-alpha, IL-6 and IL-1 beta (127). Schneemilch and Bank showed that pro-inflammatory cytokines, especially IL-6, were increased immediately after induction with balanced inhalational Trapanal/sevoflurane anesthesia and before surgery (128). Wakabayashi et al. reported that sevoflurane anesthesia markedly increased the levels of IL-6 and IL-8 (129). Kumakura et al. showed that IL-1beta, IL-6 and MCP-1 were increased after anesthesia with nitrous oxide and sevoflurane (130). Other studies have shown similar results $(131,132)$. Craddock et al., in an extensive review, have described the numerous actions by which anesthetics may affect tubulin (133).

\section{Tubulin Inhibitors and Other Chemotherapies}

Most chemotherapy drugs profoundly affect microtubules, because of their effects on mitochondrial ROS and biophoton release. Other commonly-used agents are direct inhibitors of beta-tubulin (Table II) (134-136). Taxanes, such as docetaxel and paclitaxel, are tubulin depolymerization inhibitors. Agents of the epothilone class, such as the breast cancer drug ixempra, function through the same mechanism. Vinca alkaloids, vincristine, vinblastine and vinorelbine, inhibit tubulin polymerization. Neural cells may be especially sensitive to these agents. For example, Huff et al. showed that treatment with vincristine caused disappearance of tubulin from neural cells, while cancer cells and other normal cells were not affected (137). Drugs from the halichondrin class, such as erbulin, are also polymerization inhibitors. Other chemotherapy agents have been shown to cause destruction of microtubules. In fact, a large majority of patients have received chemotherapies which have been demonstrated to 
destroy microtubules. Topoisomerase inhibitors, like tubulin inhibitors, cause apoptosis by the formation of topoisomerase I cleavage complexes (138). Topoisomerase I inhibitors such as topotecan and irinotecan are known to profoundly increase ROS (48). Doxorubicin, a topoisomerase 2 inhibitor which induces the largest increase in mitochondrial activity and is closely associated with the development of chemo brain, causes fragmentation of microtubules in cultured motor neurons $(139,140)$. Other anthracycline compounds may also disrupt microtubule organization and affect the ability of tubulin to form microtubules (141). DNA is thought to be the primary target of cisplatin, yet this agent and its analogs (carboplatin, oxaliplatin) have also been shown to enhance microtubule depolymerization and have other effects on tubulin (142). These platinum compounds cause deacetylation of alpha-tubulin and hyperphosphorylation of microtubuleassociated protein tau (143). Mitomycin C and etoposide have also been shown to affect tubulin $(144,145)$. Yokomizo et al. have shown that these four important chemotherapies, doxorubicin, cisplatin, mitomycin $\mathrm{C}$ and etoposide, increase superoxide anions, while tubulin inhibitors (vincristine) do not (146). Estramustine, an estrogenic derivative of nitrogen mustard, inhibits microtubule assembly (147). Both actinomycin-D, which binds to DNA and inhibits transcription, and 5-fluorouracil, which blocks DNA synthesis, have destructive effects on tubulin (148-150). In addition to these "classic" drugs, many newer classes of chemotherapeutic agents, such as proteasome inhibitors and tyrosine kinase inhibitors, also damage tubulin (151-155). As noted, reversal of tubulin deacetylation caused by cisplatin has also been reported to reverse symptoms of chemo brain associated with cisplatin use (143). BMS-241027, an agent which stabilizes microtubules, reverses cognitive impairments in mice (156). The selective serotonin reuptake inhibitor, fluoxetine, reverses depressive symptoms by suppression of the proinflammatory cytokines, TNF-alpha, IL-1 beta, IL-6 and IL-17 (157). Fluoxetine has been shown to reverse cognitive impairment caused by the chemotherapy drug methotrexate (158). Gaman et al. have demonstrated the causative role of oxidative stress in chemo brain induced by doxorubicin, carmustine, methotrexate or cyclophosphamide and suggested that chemo brain could be reversed by antioxidants (159). Konat et al. have shown that doxorubicin and cyclophosphamide could increase oxidative stress and cause severe attention and memory deficits in Sprague-Dawley rats, and these cognitive impairments could be reversed by antioxidants (160).

\section{Conclusion}

We argue that post-chemotherapy cognitive dysfunction (chemo brain) is caused by chemotherapy's damage to tubulin within microtubules. Chemotherapy drugs cause a marked increase in pro-inflammatory cytokines, particularly TNF-alpha, IL-1 beta, IL-6 and interferon gamma. These, in turn, stimulate reactions involving ROS production by brain mitochondria, resulting in an increase in emission of biophotons. While normal levels of biophoton release are physiological, and, in fact, may partially regulate normal biological functions, increased release is linked to neuronal pathology. For example, the peak wavelength in the ultraviolet range where biophotons cause a change in microtubule orientation is at $280 \mathrm{~nm}$, which is also the peak absorption wavelength of tryptophan. Biophoton release at this wavelength results in excess tryptophan metabolism along the kynurenine pathway, and the production of increased levels of neurotoxic metabolites. There is much evidence that microtubules are key to neurocognitive development, and abnormalities of microtubules are linked to deficiencies in cognition and memory. Anesthetics, which frequently cause a post-anesthesia cognitive dysfunction similar to chemo brain, have profound effects on tubulin. Most importantly, almost all the frequently-used chemotherapeutic drugs have destructive direct or indirect effects on tubulin. Reversal of the destructive effects on tubulin that are caused by these chemotherapies can result in alleviation of the cognitive impairments caused by these agents.

\section{Conflicts of Interest}

The Authors have no disclosures regarding this study.

\section{Authors' Contributions}

Both Authors have met all of the following four criteria: i) Substantial contributions to the conception or design of the work or the acquisition, analysis, or interpretation of data for the work. ii) Drafting the work or revising it critically for important intellectual content. iii) Final approval of the version to be published. iv) Agreement to be accountable for all aspects of the work in ensuring that questions related to the accuracy or integrity of any part of the work are appropriately investigated and resolved.

\section{References}

1 Jean-Pierre P and McDonald B: Neuroepidemiology of cancer and treatment-related neurocognitive dysfunction in adult-onset cancer patients and survivors. In: Handbook of clinical neurology. Elsevier, pp. 297-309, 2016.

2 Peterson CC, Johnson CE, Ramirez LY, Huestis S, Pai AL, Demaree HA and Drotar D: A meta-analysis of the neuropsychological sequelae of chemotherapy-only treatment for pediatric acute lymphoblastic leukemia. Pediatr Blood Cancer 51(1): 99-104, 2008. PMID: 18322925. DOI: 10.1002/pbc.21544

3 Tannock IF, Ahles TA, Ganz PA and van Dam FS: Cognitive impairment associated with chemotherapy for cancer: Report of a workshop. J Clin Oncol 22(11): 2233-2239, 2004. PMID: 15169812. DOI: $10.1200 / J C O .2004 .08 .094$ 
4 Iyer NS, Balsamo LM, Bracken MB and Kadan-Lottick NS: Chemotherapy-only treatment effects on long-term neurocognitive functioning in childhood ALL survivors: A review and meta-analysis. Blood 126(3): 346-353, 2015. PMID: 26048910. DOI: 10.1182/blood-2015-02-627414

5 Buizer AI, de Sonneville LM and Veerman AJ: Effects of chemotherapy on neurocognitive function in children with acute lymphoblastic leukemia: A critical review of the literature. Pediatr Blood Cancer 52(4): 447-454, 2009. PMID: 19061221. DOI: $10.1002 / p b c .21869$

6 Kadan-Lottick NS, Zeltzer LK, Liu Q, Yasui Y, Ellenberg L, Gioia G, Robison LL and Krull KR: Neurocognitive functioning in adult survivors of childhood non-central nervous system cancers. J Natl Cancer I 102(12): 881-893, 2010. PMID: 20458059. DOI: $10.1093 /$ jnci/djq156

7 Butler RW and Haser JK: Neurocognitive effects of treatment for childhood cancer. Ment Retard Dev D R 12(3): 184-191, 2006. PMID: 17061287. DOI: 10.1002/mrdd.20110

8 Rodin G and Ahles TA: Accumulating evidence for the effect of chemotherapy on cognition. J Clin Oncol 30(29): 3568-3569, 2012. PMID: 22927529. DOI: 10.1200/JCO.2012.43.5776

9 Kesler SR and Blayney DW: Neurotoxic effects of anthracycline$v s$ nonanthracycline-based chemotherapy on cognition in breast cancer survivors. JAMA Oncol 2(2): 185-192, 2016. PMID: 26633037. DOI: 10.1001/jamaoncol.2015.4333

10 Koppelmans V, Breteler M, Boogerd W, Seynaeve C, Gundy C and Schagen S: Neuropsychological performance in survivors of breast cancer more than 20 years after adjuvant chemotherapy. $\mathbf{J}$ Clin Oncol 30(10): 1080-1086, 2012. PMID: 22370315. DOI: 10.1200/JCO.2011.37.0189

11 Ahles TA, Saykin AJ, Furstenberg CT, Cole B, Mott LA, Skalla $\mathrm{K}$, Whedon $\mathrm{MB}$, Bivens $\mathrm{S}$, Mitchell $\mathrm{T}$ and Greenberg ER: Neuropsychologic impact of standard-dose systemic chemotherapy in long-term survivors of breast cancer and lymphoma. J Clin Oncol 20(2): 485-493, 2002. PMID: 11786578. DOI: $10.1200 / \mathrm{JCO} .2002 .20 .2 .485$

12 Rendeiro C, Sheriff A, Bhattacharya TK, Gogola JV, Baxter JH, Chen H, Helferich WG, Roy EJ and Rhodes JS: Long-lasting impairments in adult neurogenesis, spatial learning and memory from a standard chemotherapy regimen used to treat breast cancer. Behav Brain Res 315: 10-22, 2016. PMID: 27478140. DOI: 10.1016/j.bbr.2016.07.043

13 Tangpong J, Cole MP, Sultana R, Joshi G, Estus S, Vore M, Clair WS, Ratanachaiyavong S, Clair DKS and Butterfield DA: Adriamycin-induced, TNF- $\alpha$-mediated central nervous system toxicity. Neurobiol Dis 23(1): 127-139, 2006. PMID: 16697651. DOI: 10.1016/j.nbd.2006.02.013

14 Reers S, Pfannerstill A-C, Rades D, Maushagen R, Andratschke $\mathrm{M}$, Pries R and Wollenberg B: Cytokine changes in response to radio-/chemotherapeutic treatment in head and neck cancer. Anticancer Res 33(6): 2481-2489, 2013. PMID: 23749899.

15 Edwardson DW, Boudreau J, Mapletoft J, Lanner C, Kovala AT and Parissenti AM: Inflammatory cytokine production in tumor cells upon chemotherapy drug exposure or upon selection for drug resistance. PloS One 12(9): e0183662, 2017. PMID: 28915246. DOI: 10.1371/journal.pone.0183662

16 Penson RT, Kronish K, Duan Z, Feller AJ, Stark P, Cook SE, Duska LR, Fuller AF, Goodman A and Nikrui N: Cytokines IL$1 \beta$, IL-2, IL-6, IL-8, MCP-1, GM-CSF and TNF $\alpha$ in patients with epithelial ovarian cancer and their relationship to treatment with paclitaxel. Int J Gynecol Cancer 10(1): 33-41, 2000. PMID: 11240649. DOI: 10.1046/j.1525-1438.2000.00003.x

17 Pusztai L, Mendoza TR, Reuben JM, Martinez MM, Willey JS, Lara J, Syed A, Fritsche HA, Bruera E and Booser D: Changes in plasma levels of inflammatory cytokines in response to paclitaxel chemotherapy. Cytokine 25(3): 94-102, 2004. DOI: 10.1016/j.cyto.2003.10.004

18 Povoski SP, Lipari AM, Agnese DM, Farrar WB, Yee LD and Carson III WE: Inflammatory cytokines and comorbidity development in breast cancer survivors versus noncancer controls: Evidence for accelerated aging? J Clin Oncol 35(2): 149, 2017. PMID: 14698135. DOI: 10.1016/j.cyto.2003.10.004

19 Jones VS, Huang R-Y, Chen L-P, Chen Z-S, Fu L and Huang R$\mathrm{P}$ : Cytokines in cancer drug resistance: Cues to new therapeutic strategies. BBA-Rev Cancer 1865(2): 255-265, 2016. PMID: 26993403. DOI: 10.1016/j.bbcan.2016.03.005

20 Sordillo PP and Helson L: Curcumin and cancer stem cells: Curcumin has asymmetrical effects on cancer and normal stem cells. Anticancer Res 35(2): 599-614, 2015. PMID: 25667437.

21 Burkholder B, Huang R-Y, Burgess R, Luo S, Jones VS, Zhang W, Lv Z-Q, Gao C-Y, Wang B-L and Zhang Y-M: Tumor-induced perturbations of cytokines and immune cell networks. BBA-Rev Cancer 1845(2): 182-201, 2014. PMID: 24440852. DOI: 10.1016/j.bbcan.2014.01.004

22 de Visser KE and Jonkers J: Towards understanding the role of cancer-associated inflammation in chemoresistance. Curr Pharm 15(16): 1844-1853, 2009. PMID: 19519427. DOI: 10.2174/1381 61209788453239

23 Ho EA and Piquette-Miller M: Regulation of multidrug resistance by pro-inflammatory cytokines. Curr Cancer Drug Tar 6(4): 295-311, 2006. PMID: 16848721. DOI: 10.2174/156800906777441753

24 Shimabukuro-Vornhagen A, Gödel P, Subklewe M, Stemmler HJ, Schlößer HA, Schlaak M, Kochanek M, Böll B and von Bergwelt-Baildon MS: Cytokine release syndrome. J Immunother Cancer 6(1): 56, 2018. PMID: 29907163. DOI: 10.1186/s40425018-0343-9

25 Sordillo PP and Helson L: Curcumin suppression of cytokine release and cytokine storm. A potential therapy for patients with Ebola and other severe viral infections. In Vivo 29(1): 1-4, 2015. PMID: 25600522.

26 Lee DW, Gardner R, Porter DL, Louis CU, Ahmed N, Jensen M, Grupp SA and Mackall CL: Current concepts in the diagnosis and management of cytokine release syndrome. Blood 124(2): 188-195, 2014. PMID: 31265503. DOI: 10.1182/blood-2016-07-730689

27 Wang X-M, Walitt B, Saligan L, Tiwari AF, Cheung CW and Zhang Z-J: Chemobrain: A critical review and causal hypothesis of link between cytokines and epigenetic reprogramming associated with chemotherapy. Cytokine 72(1): 86-96, 2015. PMID: 25573802. DOI: 10.1016/j.cyto.2014.12.006

28 Ganz PA, Bower J, Kwan L, Castellon S, Silverman D, Geist C, Breen E, Irwin $\mathrm{M}$ and Cole $\mathrm{S}$ : Does tumor necrosis factor-alpha (TNF- $\alpha$ ) play a role in post-chemotherapy cerebral dysfunction? Brain Behavior Immun 30: S99-S108, 2013. PMID: 22884417. DOI: $10.1016 /$ j.bbi.2012.07.015

29 Vichaya EG, Chiu GS, Krukowski K, Lacourt TE, Kavelaars A, Dantzer R, Heijnen CJ and Walker AK: Mechanisms of chemotherapy-induced behavioral toxicities. Front Neurosci 9: 131, 2015. PMID: 25954147. DOI: 10.3389/fnins.2015.00131

30 Cheung YT, Lim SR, Ho HK and Chan A: Cytokines as mediators of chemotherapy-associated cognitive changes: Current 
evidence, limitations and directions for future research. PloS One 8(12): e81234, 2013. PMID: 24339912. DOI: 10.1371/journal. pone. 0081234

31 Cheung Y, Ng T, Shwe M, Ho H, Foo K, Cham M, Lee J, Fan G, Tan Y and Yong W: Association of proinflammatory cytokines and chemotherapy-associated cognitive impairment in breast cancer patients: A multi-centered, prospective, cohort study. Ann Oncol 26(7): 1446-1451, 2015. PMID: 25922060. DOI: 10.1093/annonc/mdv206

32 Dunlop RJ and Campbell CW: Cytokines and advanced cancer. J Pain Symptom Manage 20(3): 214-232, 2000. PMID: 11018340. DOI: 10.1016/s0885-3924(00)00199-8

33 Capuron L, Ravaud A and Dantzer R: Timing and specificity of the cognitive changes induced by interleukin- 2 and interferon- $\alpha$ treatments in cancer patients. Psychosom Med 63(3): 376-386, 2001. PMID: 11382265. DOI: 10.1097/00006842-20010500000007

34 Birkedal-Hansen $\mathrm{H}$ : Role of cytokines and inflammatory mediators in tissue destruction. J Periodontal Res 28(7): 500-510, 1993. PMID: 8263720. DOI: 10.1111/j.1600-0765.1993.tb02113.x

35 Dayer J-M and Burger D: Cytokines and direct cell contact in synovitis: Relevance to therapeutic intervention. Arthritis Res Ther 1(1): 17, 1999. PMID: 11094408. DOI: 10.1186/ar5

36 Bohmwald K, Gálvez NM, Canedo-Marroquín G, Pizarro-Ortega MS, Andrade-Parra C, Gómez-Santander F and Kalergis AM: Contribution of cytokines to tissue damage during human respiratory syncytial virus infection. Front Immunol 10, 2019. PMID: 30936869. DOI: 10.3389/fimmu.2019.00452

37 Joshi G, Sultana R, Tangpong J, Cole MP, St Clair DK, Vore M, Estus $\mathrm{S}$ and Butterfield DA: Free radical mediated oxidative stress and toxic side effects in brain induced by the anti-cancer drug adriamycin: Insight into chemobrain. Free Radic Res 39(11): 1147-1154, 2005. PMID: 16298740. DOI: 10.1080/ 10715760500143478

38 Joshi G, Aluise CD, Cole MP, Sultana R, Pierce W, Vore M, St Clair D and Butterfield D: Alterations in brain antioxidant enzymes and redox proteomic identification of oxidized brain proteins induced by the anti-cancer drug adriamycin: Implications for oxidative stress-mediated chemobrain. Neuroscience 166(3): 796-807, 2010. PMID: 20096337. DOI: 10.1016/j.neuroscience.2010.01.021

39 Allan SM: The role of pro-and antiinflammatory cytokines in neurodegeneration. Ann NY Acad Sci 917(1): 84-93, 2000. PMID: 11268414. DOI: 10.1111/j.1749-6632.2000.tb05373.x

40 Sordillo PP, Sordillo LA and Helson L: Bifunctional role of pro-inflammatory cytokines after traumatic brain injury. Brain Injury 30(9): 1043-1053, 2016. PMID: 27261102. DOI: $10.3109 / 02699052.2016 .1163618$

41 Allan S and Rothwell NJ: Cytokines and acute neurodegeneration Nat Rev Neurosci 2(10): 734-744, 2001. PMID: 11584311 . DOI: $10.1038 / 35094583$

42 Romi F, Helgeland G and Gilhus NE: Serum levels of matrix metalloproteinases: Implications in clinical neurology. EurNeurol 67(2): 121-128, 2012. PMID: 22262194. DOI: 10.1159/000334862

43 Duits FH, Hernandez-Guillamon M, Montaner J, Goos JD, Montañola A, Wattjes MP, Barkhof F, Scheltens P, Teunissen $\mathrm{CE}$ and van der Flier WM: Matrix metalloproteinases in Alzheimer's disease and concurrent cerebral microbleeds. J Alzheimers Dis 48(3): 711-720, 2015. PMID: 26402072. DOI: 10.3233/JAD-143186
44 Montaner J, Alvarez-Sabín J, Molina C, Anglés A, Abilleira S, Arenillas J, González MA and Monasterio J: Matrix metalloproteinase expression after human cardioembolic stroke: Temporal profile and relation to neurological impairment. Stroke 32(8): 1759-1766, 2001. PMID: 11486102. DOI: 10.1161/01.str.32.8.1759

45 Castellazzi M, Ligi D, Contaldi E, Quartana D, Fonderico M, Borgatti L, Bellini T, Trentini A, Granieri E and Fainardi E: Multiplex matrix metalloproteinases analysis in the cerebrospinal fluid reveals potential specific patterns in multiple sclerosis patients. Front Neurol 9: 1080, 2018. PMID: 30619040. DOI: 10.3389/fneur.2018.01080

46 Yang D, Elner SG, Bian Z-M, Till GO, Petty HR and Elner VM: Pro-inflammatory cytokines increase reactive oxygen species through mitochondria and NADPH oxidase in cultured RPE cells. Exp Eye Res 85(4): 462-472, 2007. PMID: 17765224. DOI: $10.1016 /$ j.exer.2007.06.013

47 Loehr JA, Abo-Zahrah R, Pal R and Rodney GG: Cytokine stimulation induces nox2-dependent ROS production and decreases muscle function. Biophys J 108(2): 424a, 2015. DOI: 10.1016/j.bpj.2014.11.2320

48 Conklin KA: Chemotherapy-associated oxidative stress: Impact on chemotherapeutic effectiveness. Integr Cancer Ther 3(4): 294-300, 2004. PMID: 15523100. DOI: 10.1177/1534 735404270335

49 Voeikov V: Reactive oxygen species, water, photons and life. Riv Biol 94(2): 237-258, 2001. PMID: 11702650.

50 Bischof M: Biophotons-the light in our cells. J Optomenic Phototherapy, 2005. Available at: https://www.bibliote capleyades.net/ciencia/ciencia_fuerzasuniverso06.htm [Last accessed on February 11, 2020]

51 Yang H, Villani RM, Wang H, Simpson MJ, Roberts MS, Tang $\mathrm{M}$ and Liang $\mathrm{X}$ : The role of cellular reactive oxygen species in cancer chemotherapy. J Exp Clin Cancer Res 37(1): 266, 2018. PMID: 30382874. DOI: 10.1186/s13046-018-0909-x

52 Mizutani H, Tada-Oikawa S, Hiraku Y, Kojima $M$ and Kawanishi S: Mechanism of apoptosis induced by doxorubicin through the generation of hydrogen peroxide. Life Sci 76(13): 1439-1453, 2005. PMID: 15680309. DOI: 10.1016/j.lfs.2004. 05.040

53 Tangpong J, Cole MP, Sultana R, Estus S, Vore M, St. Clair W, Ratanachaiyavong S, St. Clair DK and Butterfield DA: Adriamycin-mediated nitration of manganese superoxide dismutase in the central nervous system: Insight into the mechanism of chemobrain. J Neurochem 100(1): 191-201, 2007. PMID: 17227439. DOI: 10.1111/j.1471-4159.2006.04179.x

54 Keeney JT, Ren X, Warrier G, Noel T, Powell DK, Brelsfoard JM, Sultana R, Saatman KE, Clair DKS and Butterfield DA: Doxorubicin-induced elevated oxidative stress and neurochemical alterations in brain and cognitive decline: Protection by MESNA and insights into mechanisms of chemotherapy-induced cognitive impairment ("chemobrain"). Oncotarget 9(54): 30324, 2018. PMID: 30100992. DOI: 10.18632/oncotarget.25718

55 Wang H, Li X, Chen T, Wang W, Liu Q, Li H, Yi J and Wang $\mathrm{J}$ : Mechanisms of verapamil-enhanced chemosensitivity of gallbladder cancer cells to platinum drugs: Glutathione reduction and MRP1 downregulation. Oncol Rep 29(2): 676684, 2013. PMID: 23229154. DOI: 10.3892/or.2012.2156

56 Marullo R, Werner E, Degtyareva N, Moore B, Altavilla G, Ramalingam SS and Doetsch PW: Cisplatin induces a 
mitochondrial-ROS response that contributes to cytotoxicity depending on mitochondrial redox status and bioenergetic functions. PloS One 8(11): e81162, 2013. PMID: 24260552. DOI: $10.1371 /$ journal.pone.0081162

57 Kim J, Xu M, Xo R, Mates A, Wilson G, Pearsall IV A and Grishko V: Mitochondrial DNA damage is involved in apoptosis caused by pro-inflammatory cytokines in human OA chondrocytes. Osteoarthr Cartilage 18(3): 424-432, 2010. PMID: 19822235. DOI: 10.1016/j.joca.2009.09.008

58 López-Armada MJ, Caramés B, Martin M, Cillero-Pastor B, LiresDean M, Fuentes-Boquete I, Arenas J and Blanco F: Mitochondrial activity is modulated by $\mathrm{TNF} \alpha$ and IL-1 $\beta$ in normal human chondrocyte cells. Osteoarthr Cartilage 14(10): 1011-1022, 2006. PMID: 16679036. DOI: 10.1016/j.joca.2006.03.008

59 Shi $\mathrm{H}$, Shi X and Liu KJ: Oxidative mechanism of arsenic toxicity and carcinogenesis. Mol Cell Biochem 255(1-2): 6778, 2004. PMID: 14971647. DOI: 10.1023/b:mcbi.000 0007262.26044.e8

60 Popp FA, Nagl W, Li K, Scholz W, Weingärtner O and Wolf R: Biophoton emission. New evidence for coherence and DNA as source. Cell Biophys 6(1): 33-52, 1984. PMID: 6204761. DOI: 10.1007/BF02788579

61 Kobayashi M, Takeda M, Sato T, Yamazaki Y, Kaneko K, Ito $\mathrm{KI}$, Kato $\mathrm{H}$ and Inaba $\mathrm{H}$ : In vivo imaging of spontaneous ultraweak photon emission from a rat's brain correlated with cerebral energy metabolism and oxidative stress. Neurosci Res 34(2): 103-113, 1999. PMID: 10498336. DOI: 10.1016/s01680102(99)00040-1

62 Grass F and Kasper S: Humoral phototransduction: Light transportation in the blood, and possible biological effects. Med Hypotheses 71(2): 314-317, 2008. PMID: 18440721. DOI: 10.1016/j.mehy.2008.01.034

63 Scott R, Roschger P, Devaraj B and Inaba H: Monitoring a mammalian nuclear membrane phase transition by intrinsic ultraweak light emission. FEBS Lett 285(1): 97-98, 1991. PMID: 2065787. DOI: 10.1016/0014-5793(91)80733-j

64 Takeda M, Tanno Y, Kobayashi M, Usa M, Ohuchi N, Satomi $\mathrm{S}$ and Inaba $\mathrm{H}$ : A novel method of assessing carcinoma cell proliferation by biophoton emission. Cancer Lett 127(1-2): 155160, 1998. PMID: 9619872. DOI: 10.1016/s0304-3835(98) 00064-0

65 Imaizumi S, Kayama T and Suzuki J: Chemiluminescence in hypoxic brain--the first report. Correlation between energy metabolism and free radical reaction. Stroke 15(6): 1061-1065, 1984. PMID: 6506118. DOI: 10.1161/01.str.15.6.1061

66 Rahnama M, Tuszynski JA, Bokkon I, Cifra M, Sardar P and Salari V: Emission of mitochondrial biophotons and their effect on electrical activity of membrane via microtubules. J Integr Neurosci 10(01): 65-88, 2011. PMID: 21425483. DOI: $10.1142 / \mathrm{S} 0219635211002622$

67 Tuszyński J and Dixon J: Quantitative analysis of the frequency spectrum of the radiation emitted by cytochrome oxidase enzymes. Phys Rev E 64(5): 051915, 2001. PMID: 11735976. DOI: 10.1103/PhysRevE.64.051915

68 Tilbury R and Quickenden T: Spectral and time dependence studies of the ultraweak bioluminescence emitted by the bacterium Escherichia coli. Photochem Photobiol 47(1): 145150, 1988. DOI: 10.1111/j.1751-1097.1988.tb02704.x

69 Adamo AM, Llesuy SF, Pasquini JM and Boveris A: Brain chemiluminescence and oxidative stress in hyperthyroid rats.
Biochem J 263(1): 273-277, 1989. PMID: 2604697. DOI: 10.1042/bj2630273

70 Pospíšil P, Prasad A and Rác M: Role of reactive oxygen species in ultra-weak photon emission in biological systems. J Photochem Photobiol 139: 11-23, 2014. PMID: 24674863. DOI: $10.1016 / j . j p h o t o b i o l .2014 .02 .008$

71 Naveed M, Raees M, Liaqat I and Kashif M: Clastogenic ROS and biophotonics in precancerous diagnosis. Frontiers Biol 13(2): 103-122, 2018. DOI: 10.1007/s11515-018-1488-0

72 Burgos RCR, Ramautar R, Van Wijk EP, Hankemeier T, Van Der Greef $J$ and Mashaghi A: Pharmacological targeting of ROS reaction network in myeloid leukemia cells monitored by ultra-weak photon emission. Oncotarget 9(2): 2028, 2018. PMID: 29416750. DOI: 10.18632/oncotarget.23175

73 Kurian P, Obisesan T and Craddock TJ: Oxidative speciesinduced excitonic transport in tubulin aromatic networks: Potential implications for neurodegenerative disease. J Photochem Photobiol B 175: 109-124, 2017. PMID: 28865316. DOI: $10.1016 /$ j.jphotobiol.2017.08.033

74 Dyer J, Bringans S and Bryson W: Characterisation of photooxidation products within photoyellowed wool proteins: Tryptophan and tyrosine derived chromophores. Photochem Photobiol Sci 5(7): 698-706, 2006. PMID: 1682085. DOI: 10.1039/b603030k

75 Schäfer K, Goddinger D and Höcker H: Photodegradation of tryptophan in wool. J Soc Dyers Colour 113(12): 350-355, 1997. PMID: 16820857. DOI: 10.1039/b603030k

76 Walrant P and Santus R: N-formyl-kynurenine, a tryptophan photooxidation product, as a photodynamic sensitizer. Photochem Photobiol 19(6): 411-417, 1974. PMID: 4839495. DOI: $10.1111 / \mathrm{j} .1751-1097.1974 . t b 06533 . x$

77 Hamdy MS, Scott EL, Carr RH and Sanders JP: A novel photocatalytic conversion of tryptophan to kynurenine using black light as a light source. Catal Lett 142(3): 338-344, 2012. DOI: $10.1007 / \mathrm{s} 10562-012-0775-7$

78 Sheipouri D, Braidy N and Guillemin GJ: Kynurenine pathway in skin cells: Implications for UV-induced skin damage. Int J Tryptophan Res 5: IJTR-S9835, 2012. PMID: 22837645. DOI: 10.4137/IJTR.S9835

79 Andley UP and Clark BA: Generation of oxidants in the nearUV photooxidation of human lens alpha-crystallin. Invest Ophthalmol Vis Sci 30(4): 706-713, 1989. PMID: 2703311.

80 Linetsky M, Raghavan CT, Johar K, Fan X, Monnier VM, Vasavada AR and Nagaraj RH: UVA light-excited kynurenines oxidize ascorbate and modify lens proteins through the formation of advanced glycation end products implications for human lens aging and cataract formation. J Biol Chem 289(24): 17111-17123, 2014. PMID: 24798334. DOI: 10.1074/jbc.M114.554410

81 Zinger A, Barcia C, Herrero MT and Guillemin GJ: The involvement of neuroinflammation and kynurenine pathway in Parkinson's disease. Parkinson's Dis 2011: 716859, 2011. DOI: 10.4061/2011/716859

82 Sordillo LA and Sordillo PP: Optical spectroscopy of tryptophan metabolites in neurodegenerative disease. In: Neurophotonics and biomedical spectroscopy. Elsevier, pp. 137-157, 2019.

83 Campesan S, Green EW, Breda C, Sathyasaikumar KV, Muchowski PJ, Schwarcz R, Kyriacou CP and Giorgini F: The kynurenine pathway modulates neurodegeneration in a drosophila model of Huntington's disease. Curr Biol 21(11): 961-966, 2011. PMID: 21636279. DOI: 10.1016/j.cub.2011.04.028 
84 Chen Y, Stankovic R, Cullen KM, Meininger V, Garner B Coggan S, Grant R, Brew BJ and Guillemin GJ: The kynurenine pathway and inflammation in amyotrophic lateral sclerosis. Neurotox Res 18(2): 132-142, 2010. PMID: 19921535. DOI: $10.1007 / \mathrm{s} 12640-009-9129-7$

85 Sordillo LA, Zhang L, Sordillo PP and Alfano RR: Alzheimer's disease: label-free fluorescence shows increases in indoleamine 2, 3-dioxygenase (IDO) or tryptophan 2, 3-dioxygenase (TDO) activity in affected areas of the brain. Proc SPIE 108731C, 2019. DOI: $10.1117 / 12.2513384$

86 Sahm F, Oezen I, Opitz CA, Radlwimmer B, Von Deimling A, Ahrendt T, Adams S, Bode HB, Guillemin GJ and Wick W: The endogenous tryptophan metabolite and NAD+ precursor quinolinic acid confers resistance of gliomas to oxidative stress. Cancer Res 73(11): 3225-3234, 2013. PMID: 23548271. DOI: 10.1158/0008-5472.CAN-12-3831

87 Sordillo PP, Sordillo LA and Helson L: The kynurenine pathway: A primary resistance mechanism in patients with glioblastoma. Anticancer Res 37(5): 2159-2171, 2017. PMID: 28476779. DOI: 10.21873 /anticanres.11551

88 Zunszain PA, Anacker C, Cattaneo A, Choudhury S, Musaelyan K, Myint AM, Thuret S, Price J and Pariante CM: Interleukin-1 $\beta$ : A new regulator of the kynurenine pathway affecting human hippocampal neurogenesis. Neuropsychopharmacology 37(4): 939-949, 2012. PMID: 22071871. DOI: 10.1038/npp.2011.277

89 Lugo-Huitrón R, Ugalde Muñiz P, Pineda B, Pedraza-Chaverrí J, Ríos C and Pérez-De La Cruz V: Quinolinic acid: An endogenous neurotoxin with multiple targets. Oxid Med Cell Longev, 2013. PMID: 24089628. DOI: 10.1155/2013/104024

90 Guillemin GJ: Quinolinic acid, the inescapable neurotoxin. FEBS J 279(8): 1356-1365, 2012. PMID: 22248144. DOI: 10.1111/j.1742-4658.2012.08485.x

91 Rahman A, Ting K, Cullen KM, Braidy N, Brew BJ and Guillemin GJ: The excitotoxin quinolinic acid induces tau phosphorylation in human neurons. PloS One 4(7), 2009. PMID: 19623258. DOI: 10.1371/journal.pone.0006344

92 Köpke E, Tung Y-C, Shaikh S, Alonso AdC, Iqbal K and Grundke-Iqbal I: Microtubule-associated protein tau. Abnormal phosphorylation of a non-paired helical filament pool in Alzheimer disease. J Biol Chem 268(32): 24374-24384, 1993. PMID: 8226987

93 Stone TW: Kynurenines in the CNS: From endogenous obscurity to therapeutic importance. Prog Neurobiol 64(2): 185-218, 2001. PMID: 11240212. DOI: 10.1016/s0301-0082(00)00032-0

94 Lovelace MD, Varney B, Sundaram G, Franco NF, Ng ML, Pai S, Lim CK, Guillemin GJ and Brew BJ: Current evidence for a role of the kynurenine pathway of tryptophan metabolism in multiple sclerosis. Front Immunol 7(1): 246, 2016. PMID: 27540379. DOI: 10.3389/fimmu .2016.00246

95 Bordelon Y and Chesselet M-F: Early effects of intrastriatal injections of quinolinic acid on microtubule-associated protein2 and neuropeptides in rat basal ganglia. Neuroscience 93(3): 843-853, 1999. PMID: 10473250. DOI: $10.1016 / \mathrm{s} 0306-$ 4522(99)00239-0

96 Condray R, Dougherty Jr GG, Keshavan MS, Reddy RD, Haas GL, Montrose DM, Matson WR, McEvoy J, Kaddurah-Daouk $\mathrm{R}$ and Yao JK: 3-hydroxykynurenine and clinical symptoms in first-episode neuroleptic-naive patients with schizophrenia. Int J Neuropsychoph 14(6): 756-767, 2011. PMID: 21275080. DOI: $10.1017 / \mathrm{S} 1461145710001689$
97 Birner A, Platzer M, Bengesser SA, Dalkner N, Fellendorf FT, Queissner R, Pilz R, Rauch P, Maget A and Hamm C: Increased breakdown of kynurenine towards its neurotoxic branch in bipolar disorder. PloS One 12(2): e0172699, 2017. PMID: 28241062. DOI: 10.1371/journal.pone.0172699

98 Bonda DJ, Mailankot M, Stone JG, Garrett MR, Staniszewska M, Castellani RJ, Siedlak SL, Zhu X, Lee H-g and Perry G: Indoleamine 2, 3-dioxygenase and 3-hydroxykynurenine modifications are found in the neuropathology of Alzheimer's disease. Redox Rep 15(4): 161-168, 2010. PMID: 20663292. DOI: $10.1179 / 174329210 X 12650506623645$

99 Savitz J, Drevets WC, Smith CM, Victor TA, Wurfel BE, Bellgowan PS, Bodurka J, Teague TK and Dantzer R: Putative neuroprotective and neurotoxic kynurenine pathway metabolites are associated with hippocampal and amygdalar volumes in subjects with major depressive disorder. Neuropsychopharmacology 40(2): 463-471, 2015. PMID: 25074636. DOI: 10.1038/npp.2014.194

100 Solvang S-EH, Nordrehaug JE, Tell GS, Nygård O, McCann A, Ueland PM, Midttun $\varnothing$, Meyer K, Vedeler CA and Aarsland D: The kynurenine pathway and cognitive performance in community-dwelling older adults. The Hordaland health study. Brain Behav Immun 75: 155-162, 2019. PMID: 30675874. DOI: $10.1016 /$ j.bbi.2018.10.003

101 Forth S and Kapoor TM: The mechanics of microtubule networks in cell division. J Cell Biol 216(6): 1525-1531, 2017. PMID: 28490474. DOI: 10.1083/jcb.201612064

102 Conde $\mathrm{C}$ and Cáceres A: Microtubule assembly, organization and dynamics in axons and dendrites. Nature Rev Neurosci 10(5): 319-332, 2009. PMID: 19377501. DOI: 10.1038/nrn2631

103 Horio $\mathrm{T}$ and Murata T: The role of dynamic instability in microtubule organization. Front Plant Sci 5: 511, 2014. PMID: 25339962. DOI: $10.3389 /$ fpls.2014.00511

104 Meurer-Grob P, Kasparian J and Wade RH: Microtubule structure at improved resolution. Biochemistry 40(27): 80008008, 2001. PMID: 11434769. DOI: 10.1021/bi010343p

105 Huston RL: On centrioles, microtubules, and cellular electromagnetism. J Nanotechnol Eng Med 5(3): 031003, 2014. DOI: $10.1115 / 1.4028855$

106 Meunier S and Vernos I: Microtubule assembly during mitosisfrom distinct origins to distinct functions? J Cell Sci 125(12): 2805-2814, 2012. PMID: 22736044. DOI: 10.1242/jcs.092429

$107 \mathrm{Li} \mathrm{L}$ and Yang XJ: Tubulin acetylation: Responsible enzymes, biological functions and human diseases. Cell Mol Life Sci 72(22): 4237-4255, 2015. PMID: 26227334. DOI: 10.1007/ s00018-015-2000-5

108 Lasser M, Tiber J and Lowery LA: The role of the microtubule cytoskeleton in neurodevelopmental disorders. Front Cell Neurosci 12: 165, 2018. PMID: 29962938. DOI: 10.3389/ fncel.2018.00165

109 Skoge RH, Dölle C and Ziegler M: Regulation of sirt2dependent $\alpha$-tubulin deacetylation by cellular NAD levels. DNA Repair 23: 33-38, 2014. PMID: 24814981. DOI: 10.1016/ j.dnarep.2014.04.011

$110 \mathrm{Li} \mathrm{G}$, Jiang H, Chang M, Xie H and Hu L: HDAC6 $\alpha$-tubulin deacetylase: A potential therapeutic target in neurodegenerative diseases. J Neurol Sci 304(1-2): 1-8, 2011. PMID: 21377170. DOI: $10.1016 /$ j.jns.2011.02.017

111 Thar R and Kühl M: Propagation of electromagnetic radiation in mitochondria? J Theor Biol 230(2): 261-270, 2004. PMID: 15302557. DOI: $10.1016 /$ j.jtbi.2004.05.021 
112 Wilson C and González-Billault C: Regulation of cytoskeletal dynamics by redox signaling and oxidative stress: Implications for neuronal development and trafficking. Front Cell Neurosci 9: 381, 2015. PMID: 26483635. DOI: 10.3389/fncel.2015.00381

113 Knapp LT and Klann E: Role of reactive oxygen species in hippocampal long-term potentiation: Contributory or inhibitory? J Neurosci Res 70(1): 1-7, 2002. PMID: 12237859. DOI: 10.1002/jnr.10371

114 Massaad CA and Klann E: Reactive oxygen species in the regulation of synaptic plasticity and memory. Antioxid Redox Sign 14(10): 2013-2054, 2011. PMID: 20649473. DOI: 10.1089/ars.2010.3208

115 Craddock TJ, Kurian P, Tuszynski JA and Hameroff SR: Quantum processes in neurophotonics and the origin of the brain's spatiotemporal hierarchy. In: Neurophotonics and biomedical spectroscopy. Elsevier, pp. 189-213, 2019.

116 Isojima $\mathrm{Y}$, Isoshima T, Nagai K, Kikuchi K and Nakagawa H: Ultraweak biochemiluminescence detected from rat hippocampal slices. NeuroReport 6(4): 658-660, 1995. PMID: 7605921. DOI: 10.1097/00001756-199503000-00018

117 Van Wijk R, Bosman S, Ackerman J and Van Wijk E: Correlation between fluctuations in human ultra-weak photon emission and EEG alpha rhythm. NeuroQuantology 6(4), 2008. DOI: $10.14704 / \mathrm{nq} .2008 .6 .4 .201$

118 Melloni L, Molina C, Pena M, Torres D, Singer W and Rodriguez E: Synchronization of neural activity across cortical areas correlates with conscious perception. J Neurosci 27(11): 2858-2865, 2007. PMID: 17360907. DOI: 10.1523/JNEUROSCI.4623-06.2007

119 Fell $\mathrm{J}$ and Axmacher N: The role of phase synchronization in memory processes. Nat Rev Neurosci 12(2): 105-118, 2011. PMID: 21248789. DOI: $10.1038 / \mathrm{nrn} 2979$

120 Fries P: Neuronal gamma-band synchronization as a fundamental process in cortical computation. Annu Rev Neurosci 32: 209-224, 2009. PMID: 19400723. DOI: 10.1146/annurev.neuro.051508.135603

121 Pappa M, Theodosiadis N, Tsounis A and Sarafis P: Pathogenesis and treatment of post-operative cognitive dysfunction. Electronic Physician 9(2): 3768, 2017. PMID: 28465805. DOI: $10.19082 / 3768$

122 Needham M, Webb C and Bryden D: Postoperative cognitive dysfunction and dementia: What we need to know and do. Br J Anaesth 119(suppl_1): i115-i125, 2017. PMID: 29161395. DOI: 10.1093/bja/aex354

123 Rundshagen I: Postoperative cognitive dysfunction. Dtsch Arztebl Int 111(8): 119, 2014. PMID: 24622758. DOI: 10.3238/arztebl.2014.0119

124 Fitzpatrick S and Owen K: Postoperative cognitive disorders: Postoperative delirium and postoperative cognitive dysfunction. Anaesthesia tutorial of the week, 2018. Available at: https://www.wfsahq.org/components/com_virtual_library/media /8c6f8f69fda03c9f78a3eca904980fa6-atow-385-00-01.pdf [Last accessed on February 11, 2020]

125 Cibelli M, Fidalgo AR, Terrando N, Ma D, Monaco C, Feldmann M, Takata M, Lever IJ, Nanchahal J and Fanselow MS: Role of interleukin-1 $\beta$ in postoperative cognitive dysfunction. Ann Neurol 68(3): 360-368, 2010. PMID: 20818791. DOI: 10.1002 ana.22082

126 Terrando N, Monaco C, Ma D, Foxwell BM, Feldmann M and Maze M: Tumor necrosis factor- $\alpha$ triggers a cytokine cascade yielding postoperative cognitive decline. PNAS 107(47): 2051820522, 2010. PMID: 21041647. DOI: 10.1073/pnas.1014557107
127 Wu X, Lu Y, Dong Y, Zhang G, Zhang Y, Xu Z, Culley DJ, Crosby G, Marcantonio ER and Tanzi RE: The inhalation anesthetic isoflurane increases levels of proinflammatory TNF$\alpha$, IL-6, and IL-1 $\beta$. Neurobiol Aging 33(7): 1364-1378, 2012. PMID: 21190757. DOI: 10.1016/j.neurobiolaging.2010.11.002

128 Schneemilch $\mathrm{C}$ and Bank U: Release of pro-and antiinflammatory cytokines during different anesthesia procedures. Anaesthesist 26(1): 4-10, 2001. PMID: 11256129.

129 Wakabayashi S, Yamaguchi K, Kumakura S, Murakami T, Someya A, Kajiyama Y, Nagaoka I and Inada E: Effects of anesthesia with sevoflurane and propofol on the cytokine/chemokine production at the airway epithelium during esophagectomy. Int J Mol Med 34(1): 137-144, 2014. PMID: 24788377. DOI: $10.3892 /$ ijmm.2014.1762

130 Kumakura S, Yamaguchi K, Sugasawa Y, Murakami T, Kikuchi T, Inada E and Nagaoka I: Effects of nitrous oxide on the production of cytokines and chemokines by the airway epithelium during anesthesia with sevoflurane and propofol. Mol Med Rep 8(6): 1643-1648, 2013. PMID: 24145706. DOI: $10.3892 / \mathrm{mmr} .2013 .1745$

131 Peng L, Xu L and Ouyang W: Role of peripheral inflammatory markers in postoperative cognitive dysfunction (POCD): A meta-analysis. PLoS One 8(11), 2013. PMID: 24236147. DOI: 10.1371/journal.pone .0079624

132 Zheng X, Ma Z and Gu X: Plasma levels of tumor necrosis factor$\alpha$ in adolescent idiopathic scoliosis patients serve as a predictor for the incidence of early postoperative cognitive dysfunction following orthopedic surgery. Exp Ther Med 9(4): 1443-1447, 2015. PMID: 25780449. DOI: 10.3892/etm.2015.2241

133 Craddock TJ, Kurian P, Preto J, Sahu K, Hameroff SR, Klobukowski M and Tuszynski JA: Anesthetic alterations of collective terahertz oscillations in tubulin correlate with clinical potency: Implications for anesthetic action and post-operative cognitive dysfunction. Sci Rep 7(1): 1-12, 2017. PMID: 28852014. DOI: 10.1038/s41598-017-09992-7

134 Pasquier E and Kavallaris M: Microtubules: A dynamic target in cancer therapy. IUBMB Life 60(3): 165-170, 2008. PMID: 18380008. DOI: $10.1002 /$ iub. 25

135 Zhou J and Giannakakou P: Targeting microtubules for cancer chemotherapy. Curr Med Chem 5(1): 65-71, 2005. PMID: 15720262. DOI: $10.2174 / 1568011053352569$

136 Perez EA: Microtubule inhibitors: Differentiating tubulininhibiting agents based on mechanisms of action, clinical activity, and resistance. Mol Cancer Ther 8(8): 2086-2095, 2009. PMID: 19671735. DOI: 10.1158/1535-7163.MCT-09-0366

137 Huff LM, Sackett DL, Poruchynsky MS and Fojo T: Microtubule-disrupting chemotherapeutics result in enhanced proteasome-mediated degradation and disappearance of tubulin in neural cells. Cancer Res 70(14): 5870-5879, 2010. PMID: 20587529. DOI: 10.1158/0008-5472.CAN-09-4281

138 Sordet O, Goldman A and Pommier Y: Topoisomerase ii and tubulin inhibitors both induce the formation of apoptotic topoisomerase I cleavage complexes. Mol Cancer Ther 5(12): 3139-3144. PMID: 17172417. DOI: 10.1158/1535-7163.MCT06-0463

139 Necco A, Usardi C, Scarì G, Islam K, Melzner I and Vergani G: The effects of doxorubicin on embryonic spinal motoneurons cultured in vitro: Cytoskeletal response. Cytotechnology 11(2): 133-141, 1993. PMID: 7763688. DOI: $10.1007 / \mathrm{bf00749002}$ 
140 Rabkin SW and Sunga P: The effect of doxorubicin (adriamycin) on cytoplasmic microtubule system in cardiac cells. J Mol Cell Cardiol 19(11): 1073-1083, 1987. PMID: 3325651. DOI: 10.1016/s0022-2828(87)80352-8

141 Fromes Y, Gounon P, Tapiero H and Fellous A: Effects of fluoro-doxorubicin (ME2303) on microtubules: Influence of different classes of microtubule-associated proteins. J Protein Chem 15(6): 561-573, 1996. PMID: 8895103. DOI: 10.1007/ bf01908538

142 Min YJ, Poruchynsky MS, Sackett DL, Murphy B and Fojo T: Cisplatin markedly enhances microtubule depolymerization in A549 cell line compared with oxaliplatin. Cancer Res 1(1): 3335-3335, 2008.

143 Zhou L, McInnes J, Wierda K, Holt M, Herrmann AG, Jackson RJ, Wang Y-C, Swerts J, Beyens J and Miskiewicz K: Tau association with synaptic vesicles causes presynaptic dysfunction. Nat Commun 8(1): 1-13, 2017. PMID: 28492240. DOI: $10.1038 /$ ncomms 15295

144 Albertini S, Friederich U and Würgler F: Reversible inhibition of mammalian tubulin assembly in vitro and effects in saccharomyces cerevisiae D61.M by mitomycin C. Mutagenesis 4(1): 39-44, 1989. PMID: 2497300. DOI: 10.1093/mutage/4.1.39

145 Grzanka A: Estimation of changes in tubulin induced with etoposide in human leukemia cells line K-562 by immunofluorescence microscope. Neoplasma 48(1): 48-51, 2001. PMID: 11327537.

146 Yokomizo A, Ono M, Nanri H, Makino Y, Ohga T, Wada M, Okamoto T, Yodoi J, Kuwano M and Kohno K: Cellular levels of thioredoxin associated with drug sensitivity to cisplatin, mitomycin C, doxorubicin, and etoposide. Cancer Res 55(19): 4293-4296, 1995. PMID: 7671238.

147 Stearns ME and Tew KD: Estramustine binds MAP-2 to inhibit microtubule assembly in vitro. J Cell Sci 89(3): 331-342, 1988. PMID: 3198696

148 Rajagopalan R and Gurnani S: Inhibition of microtubule assembly by actinomycin d, an anti-tumour drug. Chem Biol Interact 60(2): 201-206, 1986. PMID: 3791488. DOI: 10.1016/ 0009-2797(86)90028-1

149 Gordon SR and Staley CA: Role of the cytoskeleton during injury-induced cell migration in corneal endothelium. Cell Motil Cytoskeleton 16(1): 47-57, 1990. PMID: 2354526. DOI: 10.1002/cm.970160107

150 Marchal JA, Boulaiz H, Rodriguez-Serrano F, Peran M, Carrillo E, Velez C, Dominguez J, Gomez-Vidal JA, Campos J and Gallo MA: 5-fluorouracil derivatives induce differentiation mediated by tubulin and HLA class I modulation. Med Chem 3(3): 233-239, 2007. PMID: 17504194. DOI: $10.2174 / 1573$ 40607780620671

151 Yu Y, Gaillard S, Phillip JM, Huang T-C, Pinto SM, Tessarollo NG, Zhang Z, Pandey A, Wirtz D and Ayhan A: Inhibition of spleen tyrosine kinase potentiates paclitaxel-induced cytotoxicity in ovarian cancer cells by stabilizing microtubules. Cancer Cell 28(1): 82-96, 2015. PMID: 26096845. DOI: 10.1016/j.ccell.2015. 05.009
152 Yemets A, Sheremet Y, Vissenberg K, Van Orden J, Verbelen JP and Blume YB: Effects of tyrosine kinase and phosphatase inhibitors on microtubules in arabidopsis root cells. Cell Biol Int 32(6): 630-637, 2008. PMID: 18343165. DOI: 10.1016/j.cellbi. 2008.01 .013

153 Tanabe K: Microtubule depolymerization by kinase inhibitors: Unexpected findings of dual inhibitors. Int J Mol 18(12): 2508, 2017. PMID: 29168788. DOI: 10.3390/ijms 18122508

154 Poruchynsky MS, Sackett DL, Robey RW, Ward Y, Annunziata C and Fojo T: Proteasome inhibitors increase tubulin polymerization and stabilization in tissue culture cells: A possible mechanism contributing to peripheral neuropathy and cellular toxicity following proteasome inhibition. Cell Cycle 7(7): 940-949, 2008. PMID: 18414063. DOI: 10.4161/cc.7.7.5625

155 Didier C, Merdes A, Gairin J-E and Jabrane-Ferrat N: Inhibition of proteasome activity impairs centrosome-dependent microtubule nucleation and organization. Mol Biol Cell 19(3): 1220-1229, 2008. PMID: 18094058. DOI: 10.1091/mbc.e06-12-1140

156 Barten DM, Fanara P, Andorfer C, Hoque N, Wong PA, Husted KH, Cadelina GW, DeCarr LB, Yang L and Liu V: Hyperdynamic microtubules, cognitive deficits, and pathology are improved in tau transgenic mice with low doses of the microtubule-stabilizing agent BMS-241027. J Neurosci 32(21): 7137-7145, 2012. PMID: 22623658. DOI: 10.1523/JNEUROSCI.0188-12.2012

157 Lu Y, Ho CS, Liu X, Chua AN, Wang W, McIntyre RS and Ho RC: Chronic administration of fluoxetine and pro-inflammatory cytokine change in a rat model of depression. PloS One 12(10): e0186700, 2017. PMID: 29049348. DOI: 10.1371/journal.pone.0186700

158 Lyons L, ElBeltagy M, Umka J, Markwick R, Startin C, Bennett $G$ and Wigmore P: Fluoxetine reverses the memory impairment and reduction in proliferation and survival of hippocampal cells caused by methotrexate chemotherapy. Psychopharmacology 215(1): 105-115, 2011. PMID: 21181126. DOI: $10.1007 / \mathrm{s} 00213-010-2122-2$

159 Gaman AM, Uzoni A, Popa-Wagner A, Andrei A and Petcu EB: The role of oxidative stress in etiopathogenesis of chemotherapy induced cognitive impairment (CICI)"chemobrain". Aging Dis 7(3): 307, 2016. PMID: 27330845. DOI: 10.14336/AD.2015.1022

160 Konat GW, Kraszpulski M, James I, Zhang HT and Abraham J: Cognitive dysfunction induced by chronic administration of common cancer chemotherapeutics in rats. Metab Brain Dis 23(3): 325-333, 2008. PMID: 18690526. DOI: 10.1007/s11011008-9100-y 